\title{
Formulation of the Racecadotril Capsules (100mg), Method Validation and Stability Studies.
}

\author{
Wajeeha Ishtiyaq ${ }^{1,3}$, Arslan Tariq $^{2}$, Nasir Abbas ${ }^{1}$, Kanwal Ashiq ${ }^{4}$, Mayyda Asif Bajwa ${ }^{4}$ \\ ${ }^{1}$ Department of Pharmaceutics, University College of Pharmacy, University of the Punjab Lahore, Pakistan. \\ ${ }^{2}$ Drug Regulatory Authority of Pakistan, Islamabad, Pakistan. \\ ${ }^{3}$ DHQ Hospital Kallar Syedan, Rawalpindi, Pakistan. \\ ${ }^{4}$ Faculty of Pharmaceutical Sciences Superior College, Superior University Lahore, Pakistan. \\ Corresponding author: Kanwal Ashiq kanwal.ashiq@superior.edu.pk
}

ABSTRACT

Product characterization is aimed at identifying attributes that are critical for the quality of a drug product. Such are design, analytical method validation and stability studies strengthening the product development data. Undertaken, Racecadotril 100mg Capsules for diarrheal treatment entails the entire development study. Six formulations of Racecadotril 100mg Capsules were prepared with different excipients at varied concentrations. Amongst all formulations, F6 was the best fit having a comparatively good dissolution profile with $76.9 \%$ release in 60 minutes. HPLC system was suitable as \%RSD was $0.619147 \%$ that is within the acceptance criteria. Other parameters like specificity, accuracy and recovery, precision, quantitation limit, detection limit, range, linearity, and robustness laid within the acceptance criteria. The percent degradation of Racecadotril after photolytic (sunlight for 6 hr.), oxidative (3\% H2O2), acidic and basic stress was found to be $6.5 \%, 5.8 \%, 11.4 \%$, and $28.4 \%$, respectively. The product remains unchanged after thermal stress. F6 was marked successful amongst all with HPLC method validation. Accelerated stability studies and forced degradation studies enforced that the F6 formulation of Racecadotril 100mg Capsule is stable while the model-independent approach comprising of similarity and difference factors confirmed that the undertaken product is comparable with the marketed brand.

Keywords: Racecadotril, Anti-diarrheal, HPLC, Method Validation, ICH Q2R, Stability Indicating Method, Accelerated Stability Studies.

\section{INTRODUCTION}

According to several guidelines, concomitant use of Racecadotril with oral rehydration solution is recommended for the treatment of acute diarrhea in children. Racecadotril has greater tolerability than Loperamide in patients with acute diarrhea. Maximum absorption occurs when drug is administered orally at different doses i.e $30 \mathrm{mg}, 100 \mathrm{mg}$ and $300 \mathrm{mg}$ and $\mathrm{Cmax}$ is achieved within 1 hour. According to BCS, Racecadotril belongs to Class-II drug (high permeability, low solubility). The study is aimed to design characterize a stable capsule solid dosage form of Racecadotril. Further, stability testing HPLC method validation and comparative dissolution testing for Racecadotril $100 \mathrm{mg}$ Capsules were also performed.

MATERIAL AND METHODS

HPLC method was validated on analytical parameters recommended by ICH Q2R guidelines. Forced degradation studies were performed as per Stability Indicating Method (SIM) under various conditions. Accelerated stability studies were performed and kept for 6 months. The dissolution profile of the stable formulation was compared with the innovator brand.

RESULTS AND DISCUSSION

Among six formulations of Racecadotril 100mg Capsule, F6 was the best fit having comparatively good dissolution profile with $76.9 \%$ release in 60 minutes. The HPLC system was suitable as \%RSD was $0.619147 \%$ which is within the acceptance criteria. Furthermore, analytical parameters including specificity, accuracy and recovery, precision, quantitation limit, detection limit, range, linearity and robustness lies within the acceptance criteria. The percent degradation of Racecadotril after photolytic (sunlight for $6 \mathrm{hr}$.), oxidative $\left(3 \% \mathrm{H}_{2} \mathrm{O}_{2}\right)$, acidic $(0.1 \mathrm{~N} \mathrm{HCl})$ and basic $(0.1 \mathrm{~N}$ $\mathrm{NaOH}$ ) stress was found to be $6.5 \%, 5.8 \%, 11.4 \%$ and $28.4 \%$, respectively. While the product remain unchanged after thermal stress

Table 1. Composition of different Formulations of Racecadotril 100mg capsules

\begin{tabular}{|c|c|c|c|c|c|c|c|c|}
\hline Srno & $\begin{array}{l}\text { Ingredients } \\
\end{array}$ & $\mathrm{Fl}$ & $\mathrm{F} 2$ & $\mathrm{F3}$ & $\mathrm{F} 4$ & & F6 & Role of ingredient \\
\hline & & $\overline{\mathrm{mg}}$ & $\mathrm{Mg}$ & $\mid \mathrm{mg}$ & $\overline{\mathrm{Mg}}$ & $\overline{\mathrm{mg}}$ & 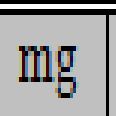 & \\
\hline 1 & Racecadototil & 100 & 100 & 100 & 100 & 100 & 100 & Active \\
\hline 2 & Maize Starch & 15 & & 10 & & & 30 & Lubicant Disinintegrant \\
\hline & Steanic acid & 2 & 2 & 1 & & & & Lubiciant \\
\hline 3 & Mg Stearate & & & & 5 & 5 & 1 & Lubricant \\
\hline 4 & Talcum porvder & 3 & 3 & 5 & & & & Gilidant \\
\hline 5 & Colloidal silicon dioxide & 0.5 & & & 3 & 1 & 0.5 & Glidant \\
\hline 6 & Lactose Monohydrate & 50 & 50 & & 50 & 45 & 66.5 & Diluent \\
\hline 7 & Microcrystalline cellulases PH 102 & 31.5 & 30 & 75 & & & & Dilluent \\
\hline 8 & Mannitol & & & & & 10 & & Diluent \\
\hline 9 & Methyl cellulose & & & & 45 & 40 & & $\overline{D i s i n t e g a n t ~}$ \\
\hline 10 & Crosscamelose sodium & & 15 & 10 & & & & Disinitegant \\
\hline & Total fill reight per capsule & 200 & 200 & 200 & 200 & 200 & 200 & \\
\hline
\end{tabular}

Table 3. Accuracy and recovery of Racecadotril HPLC assay at 50\%, 100\% and $150 \%$ standards.

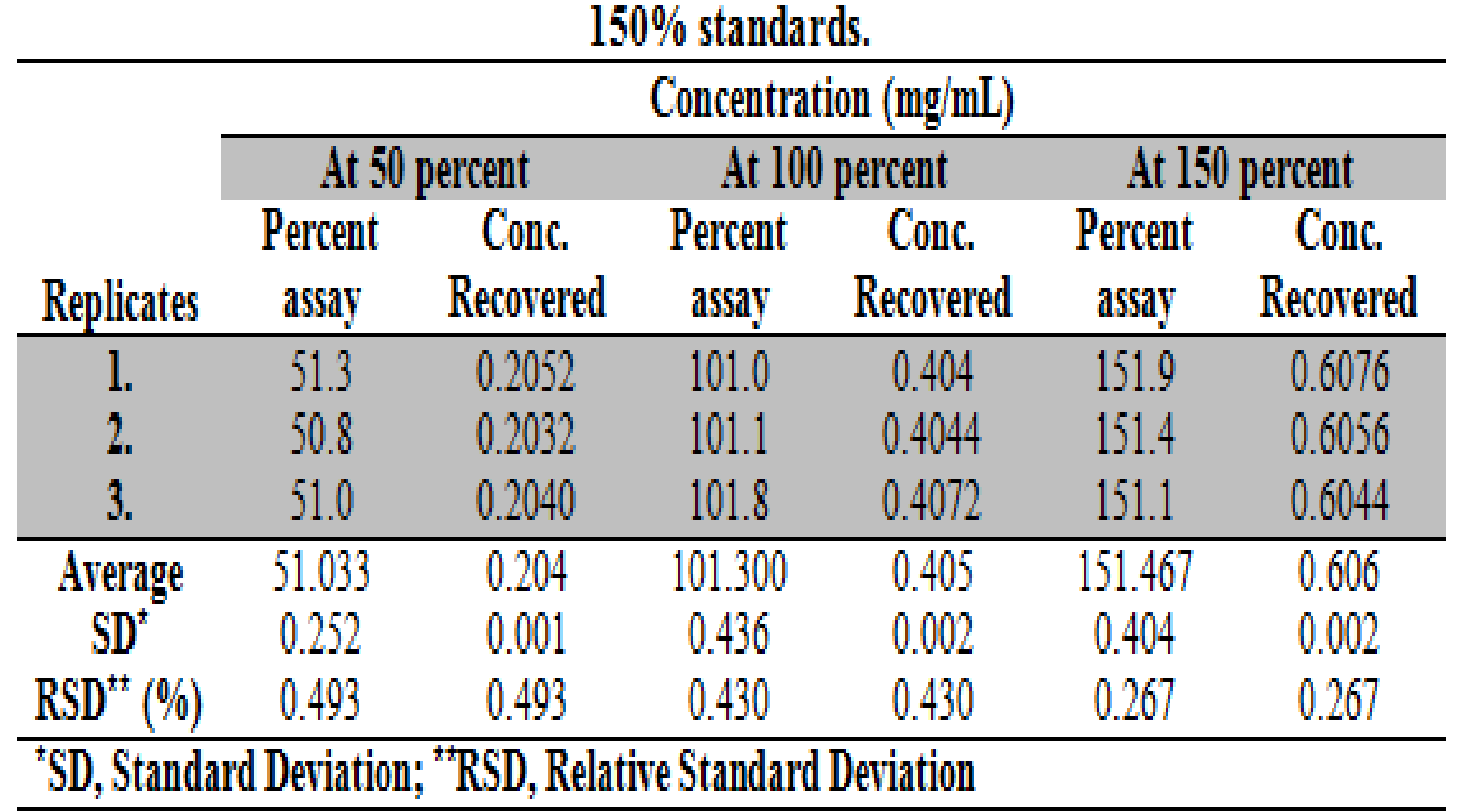

Table 2. System suitability test(SST).

\begin{tabular}{|c|c|c|c|c|}
\hline $\begin{array}{l}\text { Reference } \\
\text { standard }\end{array}$ & $\begin{array}{l}\text { Peak Arean } \\
\text { (milli rolttm) }\end{array}$ & $\begin{array}{c}\text { Jean Peak } \\
\text { Area }\end{array}$ & S.D. ${ }^{*}$ & RSS. $D_{(}(\%)^{t+1}$ \\
\hline 01 & 112436866 & \multirow{5}{*}{11204623} & \multirow{5}{*}{69373} & \multirow{5}{*}{0.619147} \\
\hline 02 & 11097937 & & & \\
\hline 03 & 11172360 & & & \\
\hline 04 & 11242053 & & & \\
\hline 05 & 11267079 & & & \\
\hline
\end{tabular}

S.D. Standard Deviatoni,"R.S.D. (\%), Percent Relative Standard Deviation
Table 4 Results of linenith at different concentration Sr. Yo. Concentration (mgg/mL) Area (milliroltmmin)

\begin{tabular}{lll}
1. & 0.1 & 2820753 \\
2. & 0.2 & 5588404 \\
3. & 0.3 & 8332772 \\
4. & 0.4 & 11089999 \\
5. & 0.5 & 14168943 \\
6. & 0.6 & 16805884 \\
7. & 0.7 & 19779778 \\
\hline
\end{tabular}

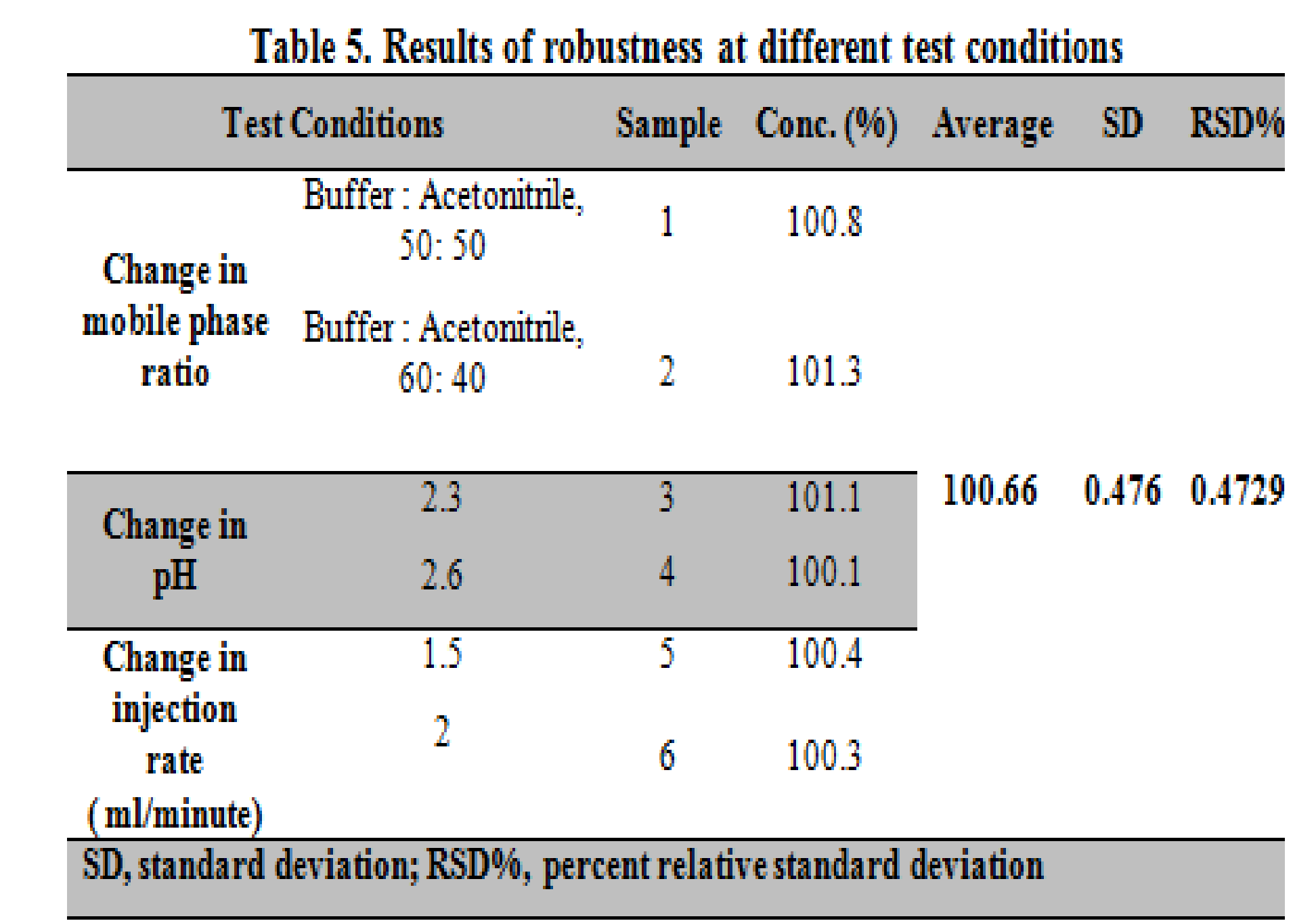

Table 6 ílimit of detection (LOD) and limit of quantitation (LOQ).

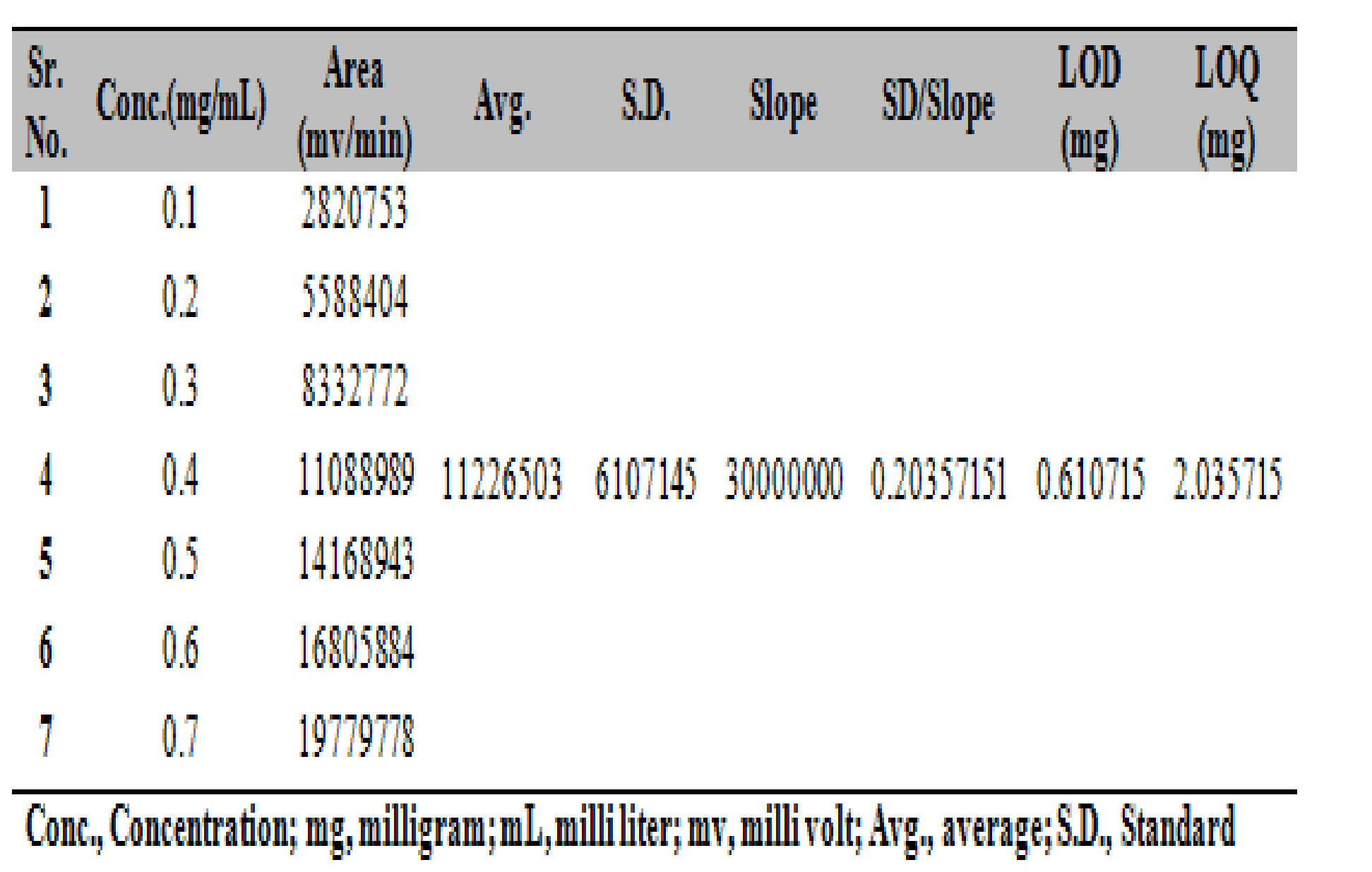

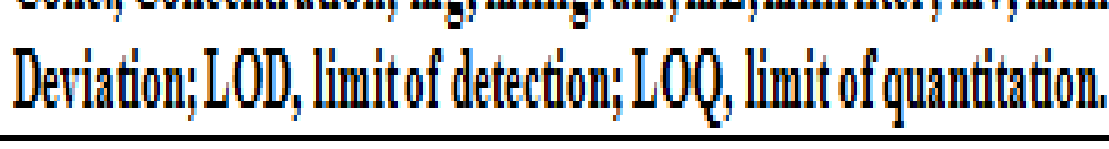

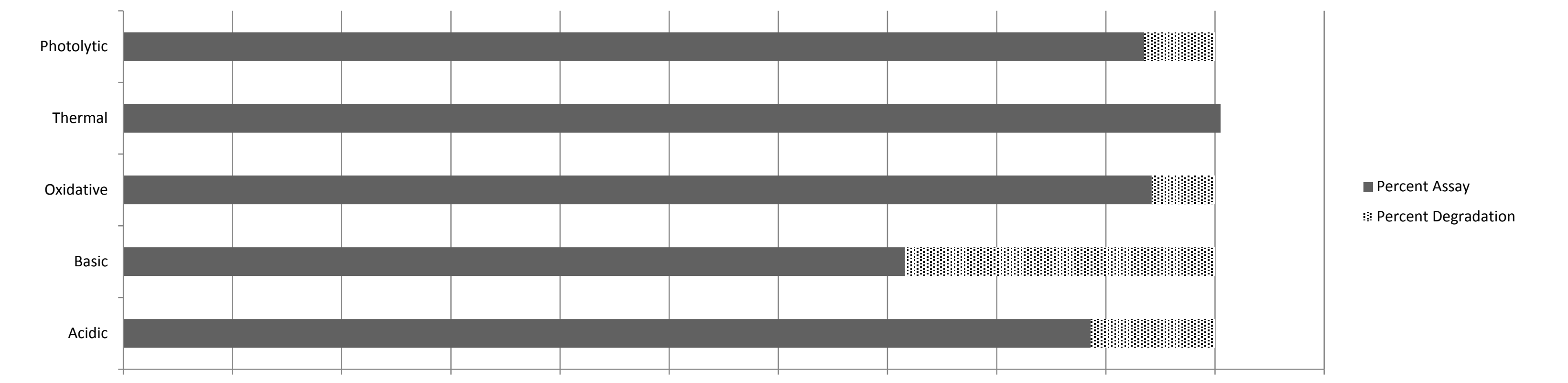

Figure 1. Forced degradation study of Racecadotril capsule 100mg. Solubility $(\mu \mathrm{g} / \mathrm{ml})$

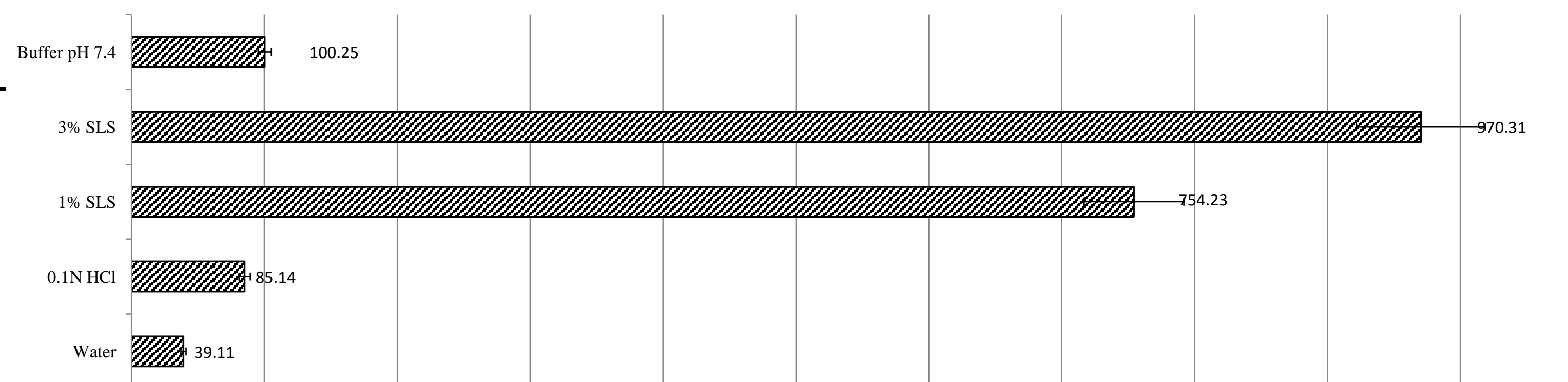

Figure 2. Graphical representation of solubility trend of Racecadotril in different solvent CONCLUSIONS

F6 was marked successful amongst all with HPLC method validation. Accelerated stability studies and forced degradation studies enforced that the F6 formulation of Racecadotril 100mg Capsule is stable. REFERENCES

Gordon M, Akobeng A. Racecadotril for acute diarrhoea in children: systematic review and meta-analyses. Archives of disease in childhood. 2016 Mar 1;101(3):234-40.

Wajeeha I, Arslan T, Nasir A, Muhammad ZUD, Kanwal A, Mayyda B, Samreen T, Mehwish $Q$, Farah A, Saleha $Y$, Afshan A. A comprehensive review on racecadotril drug International Journal of Biosciences 2019;15:405-413 